\section{SAT0182 TOCILIZUMAB S.C. - IMPROVEMENT OF THE DEPRESSIVENESS, FATIGUE AND PAIN IN RA THERAPY}

F. Behrens ${ }^{1}$, M. Englbrecht ${ }^{2}$, W. A. Biewer ${ }^{3}$, G.-R. Burmester ${ }^{4}$, M. Feuchtenberger ${ }^{5}$, J.-P. Flacke ${ }^{6}$, M. Hofmann 7 , P. Kästner ${ }^{8}$, H. Kellner ${ }^{9}$, T. Klopsch ${ }^{10}$, C. Kühne ${ }^{11}$, H.-P. Tony ${ }^{12}$, C. Amberger ${ }^{13} .{ }^{1}$ CIRI am Klinikum der Johann Wolfgang Goethe-Universität, Rheumatologie, Fraunhofer Institute for Molecular Biology and Applied Ecology IME, Project Group Translational Medicine \& Pharmacology TMP, Frankfurt/Main, ${ }^{2}$ Universitätsklinikum Erlangen, Medizinische Klinik 3, Rheumatologie und Immunologie, Erlangen, ${ }^{3}$ Rheumatologische Schwerpunktpraxis Saarbrücken, Saarbrücken, ${ }^{4}$ CharitéUniversitätsmedizin Berlin, Medizinische Klinik mit Schwerpunkt Rheumatologie und klinische Immunologie, Berlin, ${ }^{5}$ Rheumatologie/Klinische Immunologie, Kreiskliniken Altötting-Burghausen, Burghausen, ${ }^{6}$ Roche Pharma AG, GrenzachWyhlen, ${ }^{7}$ Chugai Pharma AG, Frankfurt/Main, ${ }^{8}$ MVZ Ambulantes Rheumazentrum Erfurt, Erfurt, ${ }^{9}$ Schwerpunktpraxis für Rheumatologie und Gastroenterologie, München, ${ }^{10}$ Rheumatologische Praxis, Neubrandenburg, ${ }^{11}$ Praxis, Haldensleben, ${ }^{12}$ Universitätsklinikum Würzburg, Medizinische Klinik und Poliklinik II, Schwerpunkt Rheumatologie und klinische Immunologie, Würzburg, ${ }^{13}$ Rheumatologische Gemeinschaftspraxis Dr. Pick/Dr. Amberger, Bad Neuenahr, Germany

Background: The non-interventional ARATA study (NCT02251860) observes the clinical effectiveness and safety of subcutaneous Tocilizumab [TCZ] s.c. treatment under routine conditions over a 2-year period.

Objectives: In this interim analysis, the treatment with TCZ s.c., in particular with respect to patient-reported outcomes regarding depression, fatigue and pain, was evaluated.

Methods: TCZ-naive patients (Pts) ( $\geq 18$ years) with RA, who receive TCZ s.c. treatment, could be included in the study since 2014. Demographic and diseasespecific characteristics, the progression of the disease under treatment, concomitant medications, adverse events ( $\mathrm{AE}$ ) and patient questionnaires were documented.

Results: This interim analysis (reporting date 01-FEB-2017) included 912 Pts. $75 \%$ of the Pts were female, the average age at baseline (BL) was 57 years, the median disease duration was 8 years. 319 Pts $(35 \%)$ were pretreated exclusively with sDMARD and 585 Pts (64\%) were also pretreated with bDMARD. For the readjustment, TCZ s.c. was applied for $69 \%$ without sDMARD, $31 \%$ in combination with MTX and for $66 \%$ with glucocorticoids.

In the course of the study, $65 \%$ of the Pts achieved a DAS28-BSG remission. Furthermore, the functional restrictions in day-to-day life (HAQ-DI D from BL: -0.3) improved. No new safety signals were observed.

By means of the Beck Depression Inventory (BDI-II) score (Englbrecht et al., Arthritis Care Res 2017; 69:58-66), validated for RA, the depressive symptoms could be documented. At baseline, 186 Pts (50\%) showed no, 70 (19\%) minor, 67 $(18 \%)$ moderate and $47(13 \%)$ severe depression. Under the treatment with TCZ, the depressive symptoms improved (compare figure 1).

The patients reported a significant improvement of the pain (VAS: average change from BL to week 52 by -21 points and to week 104 by -24 points) as well as the fatigue (VAS: average change from BL to week 52 by -11 points and 104 by -12 points).

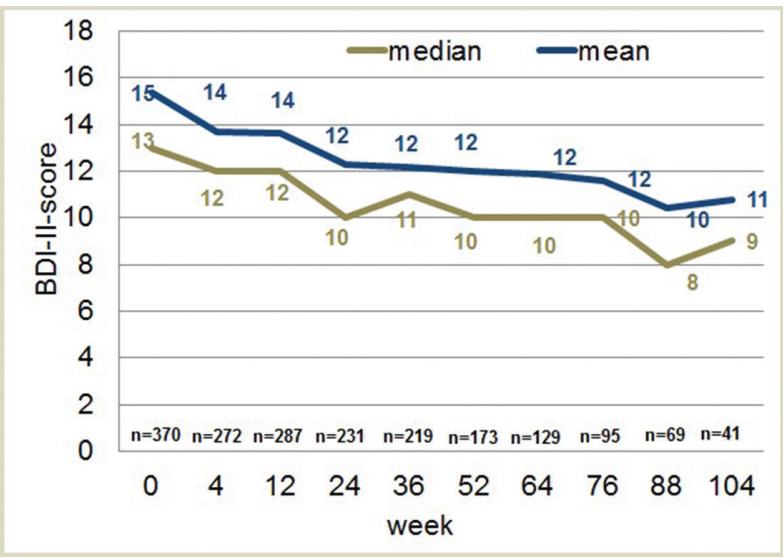

Conclusions: In the ARATA study, TCZ s.c. demonstrated an effective and persistent reduction in the disease activity of the treated RA patients. The patients confirmed improved physical functionality as well as less fatigue and pain.

Depression plays an important role in RA, as the results of BDI-II highlight, whereby the depressive symptoms also improved distinctively under treatment with TCZ s.c.
Disclosure of Interest: F. Behrens Grant/research support from: Abbvie, Pfizer, Roche, Chugai, Janssen, Novartis, Consultant for: Abbvie, Pfizer, Roche, Chugai, UCB, BMS, Celgene, MSD, Novartis, Biotest, Janssen, Genzyme, Lilly, Boehringer, Sandoz, M. Englbrecht: None declared, W. A. Biewer: None declared, G. R. Burmester Consultant for: Lilly, Pfizer, Sanofi, Roche, M. Feuchtenberger Consultant for: MSD, Roche, Abbvie, Chugai, Pfizer, UCB, J.-P. Flacke Employee of: Roche Pharma AG, M. Hofmann Employee of: Chugai Pharma Europe Ltd., P. Kästner: None declared, H. Kellner Consultant for: Roche, T. Klopsch: None declared, C. Kühne Consultant for: Celgene, Roche, Pfizer, Novartis, BMS, H.-P. Tony Consultant for: Roche Pharma, Abbvie, BMS, Chugai, Janssen, Novartis, Sanofi, Lilly, Speakers bureau: Roche Pharma, Abbvie, BMS, Chugai, Janssen, Novartis, Sanofi, Lilly, C. Amberger Consultant for: Chugai, AbbVie, Celgene, MSD, Pfizer, BMS, Hexal

DOI: 10.1136/annrheumdis-2018-eular.2176

\section{SAT0183 SWITCHING FROM ADALIMUMAB TO SARILUMAB IS ASSOCIATED WITH COMPARABLE EFFICACY BUT LOWER FUNCTIONAL IMPROVEMENT VERSUS CONTINUOUS SARILUMAB MONOTHERAPY THROUGH 48-WEEK OPEN-LABEL EXTENSION (OLE) OF THE PHASE 3 MONARCH TRIAL}

G. R. Burmester ${ }^{1}$, G. St John ${ }^{2}$, M. Iglesias-Rodriguez ${ }^{3}$, C.-C. Hü ${ }^{3}$, T. Raskina ${ }^{4}$, H. Amital ${ }^{5}$, A. Gomez Centeno ${ }^{6}$, A. Rubbert-Roth ${ }^{7} .{ }^{1}$ Department of Rheumatology and Clinical Immunology, Charité - University Medicine Berlin, Free University and Humboldt University Berlin, Berlin, Germany, ${ }^{2}$ Regeneron Pharmaceuticals, Inc, Tarrytown, NY, United States, ${ }^{3}$ Sanofi Genzyme, Bridgewater, NJ, United States, ${ }^{4}$ Kemerov State Medical Academy of Roszdrav, Kemerovo, Russian Federation, ${ }^{5}$ Sheba Medical Center, Tel-Hashomer, Israel, ${ }^{6}$ Corporació Sanitària Parc Taulí, Barcelona, Spain, ${ }^{7}$ Klinik fuer Rheumatologie, Kantonsspital St. Gallen, St. Gallen, Switzerland

Background: Sarilumab is a human mAb blocking IL-6R $\alpha$. In Phase 3 MONARCH (NCT02332590), sarilumab (200 mg subcutaneously [SC] every 2 wks [q2w] for 24 wks) was superior to adalimumab monotherapy (40 mg SC q2w) in reducing disease activity and improving physical function in RA patients (pts) with an inadequate response or intolerance to methotrexate.

Objectives: To assess whether pts who achieved clinical response on sarilumab during MONARCH sustained this response in the OLE and to evaluate efficacy and safety of switching from adalimumab to sarilumab vs continuous sarilumab treatment.

Methods: Pts completing the double-blind phase of $\mathrm{MONARCH}$ were eligible for the ongoing OLE, in which all pts receive sarilumab (200 mg SC q2w) for a maximum duration of 276 wks. Disease activity, physical function, and safety were assessed regularly.

Results: $320 / 369$ Pts enrolled in MONARCH entered the OLE; pts either switched from adalimumab to sarilumab $(n=155)$ or continued on sarilumab $(n=165)$. At OLE entry (Wk 24 of the double-blind phase), the mean $\triangle$ from baseline DAS28-ESR was -2.28 in the switch group vs -3.36 in the continuation group, and by Wk 48 was -4.06 vs -4.18 , respectively. By Wk 48 of the OLE, the proportion of pts in the switch and continuation groups who achieved DAS28-ESR $\leq 3.2$ was $61.3 \%$ vs $61.2 \%$, DAS28-ESR $<2.6$ was $43.9 \%$ vs $49.7 \%$, and DAS 28 CRP $<2.6$ was $52.9 \%$ vs $52.1 \%$, respectively. From OLE entry to Wk 48 , mean $\mathrm{HAQ}-\mathrm{DI}$ improved in the switch group from 1.21 to 0.91 , but did not reach the leve of improvements in the continuation group (1.01 to 0.84 ). See table 1 for ACR responses. After 166 vs 182 cumulative patient-years exposure in the switch vs continuation groups, treatment-emergent adverse events (TEAEs) were observed in $76.1 \%$ vs $70.9 \%$, serious TEAEs in $11.0 \%$ vs $3.6 \%$, and infections in $41.9 \%$ vs $35.8 \%$, respectively, with 2 deaths in the switch group (malignancy; cerebrovascular accident) and 1 death (subarachnoid hemorrhage) in the continuation group. No GI related AEs (ulcerations, perforations or diverticulitis) were observed in either group.

\begin{tabular}{|c|c|c|c|c|}
\hline & Wk 0 OLE & & Wk 48 OLE & \\
\hline & $\begin{array}{l}\text { Switch group: } \\
\text { Adalimumab } 40 \\
\text { mg q2w } \rightarrow \\
\text { Sarilumab } 200 \mathrm{mg} \\
\text { q2w } \\
(\mathrm{N}=155)\end{array}$ & $\begin{array}{l}\text { Continuation } \\
\text { group: } \\
\text { Sarilumab } \\
200 \text { mg q2w } \\
(\mathrm{N}=165)\end{array}$ & $\begin{array}{l}\text { Switch group: } \\
\text { Adalimumab } 40 \\
\text { mg q2w } \rightarrow \\
\text { Sarilumab } 200 \mathrm{mg} \\
\text { q2w } \\
(\mathrm{N}=155)\end{array}$ & $\begin{array}{l}\text { Continuation } \\
\text { group: } \\
\text { Sarilumab } \\
200 \text { mg q2w } \\
(\mathrm{N}=165)\end{array}$ \\
\hline $\begin{array}{l}\text { ACR20/50/ } \\
70, \% \\
\text { responders }\end{array}$ & $68.4 / 35.5 / 14.2$ & $79.4 / 50.9 / 26.1$ & $77.4 / 59.4 / 38.1$ & $81.2 / 63.0 / 41.8$ \\
\hline $\begin{array}{l}\text { HAQ-DI, } \\
\text { mean }\end{array}$ & 1.21 & 1.01 & 0.91 & 0.84 \\
\hline
\end{tabular}

